\title{
How Uncertainty about War Outcomes Affects War Onset
}

\section{Citation}

Bas, M. A., and R. J. Schub. 2014. "How Uncertainty About War Outcomes Affects War Onset." Journal of Conflict Resolution (October 27). doi:10.1177/0022002714553110.

\section{Published Version}

doi:10.1177/0022002714553110

\section{Permanent link}

http://nrs.harvard.edu/urn-3:HUL.InstRepos:27115555

\section{Terms of Use}

This article was downloaded from Harvard University's DASH repository, and is made available under the terms and conditions applicable to Open Access Policy Articles, as set forth at http:// nrs.harvard.edu/urn-3:HUL.InstRepos:dash.current.terms-of-use\#OAP

\section{Share Your Story}

The Harvard community has made this article openly available.

Please share how this access benefits you. Submit a story.

Accessibility 


\title{
How Uncertainty about War Outcomes Affects War Onset
}

\author{
Muhammet A. Bas* \\ Department of Government \\ Harvard University
}

\author{
Robert J. Schub \\ Department of Government \\ Harvard University
}

\begin{abstract}
In canonical accounts of war, conflict outcomes are inherently uncertain. Contesting literatures posit that this uncertainty, arising from stochastic elements of the war-fighting process, may induce conflict due to greater risks of miscalculation or foster peace by breeding caution. We theorize that states, on average, exhibit prudence when confronting greater uncertainty. Despite its conceptual importance, extant proxies for uncertainty at various levels of analysissuch as polarity, balance-of-power, system concentration, and dyadic relative capabilitiesare imprecise and theoretically inappropriate indicators. To overcome this shortcoming, we theorize the conditions that elevate the magnitude of uncertainty over conflict outcomes and introduce a novel measure that captures this uncertainty within any $k$-state system. Through extensive empirical analysis, we confirm uncertainty's pacifying effect, and show how this effect operates at different levels of analysis.
\end{abstract}

*We would like to acknowledge the support of the Weatherhead Center for International Affairs at Harvard University. This paper was previously presented at the 2013 meeting of the American Political Science Association and the 2012 meeting of the Peace Science Society. We would like to thank Elena McLean, Beth Simmons, Kris Ramsay, Ahmer Tarar, Dustin Tingley and Yuri Zhukov for valuable comments. All errors remain our own. 
Reflecting on the uncertainty that accompanies military conflict, Churchill wrote "The Statesman who yields to war fever must realise that once the signal is given, he is no longer the master of policy but the slave of unforeseeable and uncontrollable events." ${ }^{1}$ Does awareness of this inherent uncertainty over a conflict's course and outcome affect whether conflict occurs at all? If so, is this a pacifying or incendiary effect? Prominent debates in security studies address whether outcome uncertainty induces conflict through miscalculation or peace due to caution and whether uncertainty is a function of dyadic or multilateral factors (Waltz, 1979; Blainey, 1988; Kugler and Lemke, 1996). This article aims to settle these debates, showing that greater uncertainty over war outcomes reduces the likelihood of war occurrence and that the optimal conception and measurement of uncertainty incorporates multilateral factors. We develop a theory specifying the conditions that elevate the magnitude of outcome uncertainty and linking this uncertainty to state behavior. Our theory emphasizes the complexity of the estimation task confronting a war initiating state when evaluating the conflict entry and alignment choices of third party actors. Specifically, outcome uncertainty increases with wider power parity as there are more potential belligerents with sufficient military capabilities to meaningfully alter war's outcome. When facing greater uncertainty, states behave cautiously. Building from these theoretically informed foundations, we introduce a new measure of uncertainty enabling tests and confirmation of the hypothesis that the "unforeseeable" nature of conflict is a cause of peace.

To clarify the scope of our analysis, consider uncertainty's pivotal role across the international conflict literature. At least three broad types of uncertainty are invoked: uncertainty over states' intentions, uncertainty over states' resolve or material capabilities, and uncertainty over conflict outcomes. The first, uncertain intentions, underpins the security dilemma (Jervis, 1978). A peer state acquiring arms is problematic given the uncertain objective-offensive or defensive —of that actor. Mistaken perceptions may culminate in spiraling hostilities or deterrence failures (Jervis,

\footnotetext{
${ }^{1}$ Quoted in Mitzen and Schweller (2011).
} 
1976; Kydd, 1997; Trager, 2010). The second, uncertainty concerning a state's resolve or capabilities, when coupled with incentives to misrepresent the truth, generate information asymmetries and one of the primary rationalist explanations for war (Fearon, 1995; Powell, 1999; Slantchev, 2003; Fey and Ramsay, 2011). Unfortunately, both types of uncertainty are difficult to measure and consequently relegated to the error term in statistical analyses of conflict (Gartzke, 1999).

Our study concerns the third form, Churchill's uncertainty over conflict outcomes. When war is depicted as a costly lottery, the uncertainty about its outcome persists even in complete information settings. Hence, uncertainty over capabilities will affect uncertainty over outcomes, but the latter persists even if the former is absent. Though employed as a modeling convenience, the randomness captured by the lottery formulation is deeply grounded in both theoretical and historical accounts of war. Clausewitz's (1976, p. 119) discussion of friction provides an exposition of the concept. Schelling (1966, p. 93) echoes a similar sentiment:

Violence, especially war, is a confused and uncertain activity, highly unpredictable, depending on decisions made by fallible human beings organized into imperfect governments, depending on fallible communications and warning systems and on the untested performance of people and equipment.

Scholars of international relations have long disputed the effects of outcome uncertainty. At a strictly bilateral level the consensus is that dyads with roughly equivalent capabilities, which are associated with high outcome uncertainty, are more likely to have conflict (Kugler and Lemke, 1996; Reed, 2003). However, the association between bilateral parity and bilateral conflict provides a limited, and ultimately misleading, understanding of how outcome uncertainty affects war onset. As others have emphasized (Bueno de Mesquita, 1983; Maoz, 1996; Sobek and Clare, 2013), dyadic interactions do not occur in isolation. Estimates of uncertainty about a war's outcome should account for multilateral factors. Which multilateral factors matter and what their implications are for linking outcome uncertainty to state behavior are subject to debate (for example, Singer, Bremer and Stuckey 1972; Bueno de Mesquita 1981; Huth, Bennett and Gelpi 1992; 
Bennett and Stam 2004). We bring clarity to this often muddled debate by theorizing how attributes such as polarity, the balance of power, and estimation complexity relate to uncertainty's magnitude and conflict likelihood. Contrary to the conclusions of strictly bilateral studies, we anticipate that higher outcome uncertainty reduces the probability of conflict. The logic is as follows: given that conflict does not occur in isolation, potential belligerents must assess the probable reactions of multiple states in the event of violence onset. As elaborated upon in the theory section, outcome uncertainty is elevated when there is relative power parity across many third party actors, as each state's entry and alignment choices may meaningfully alter the conflict's outcome. Late 19th-century Europe typifies this scenario. We expect that state leaders exercise prudence when confronting such uncertainty. In contrast, a stark hierarchical distribution of power simplifies the strategic setting for conflict initiators. The Cold War era is representative of a low uncertainty context. Everything else being equal, certainty induces state leaders to exhibit less caution due to the relative simplicity of this estimation task, thus increasing the probability of conflict.

Despite its theoretical importance, no compelling multilateral measure of uncertainty exists to test our hypotheses. Must outcome uncertainty be left to the error term as well? Working from the common costly lottery assumption, we build a flexible measure of uncertainty that can be tailored to include any theoretically appropriate set of states ranging from the two constituent states of a dyad to all countries in the international system. After demonstrating desirable properties of the new measure as compared to alternative extant proxies, we subject our hypotheses to extensive empirical tests at multiple levels of analysis and find strong support for our contention that greater outcome uncertainty, particularly at the system level, is a cause of peace.

The remainder of the article proceeds as follows. The next section theorizes the links between uncertainty over conflict outcomes and conflict initiation, deduces our hypotheses, and connects this discussion to the existing literature. We then outline the construction of the new measure, high- 
lighting its theoretical grounding, flexibility, and behavior. The subsequent section introduces the research design, describes the results, and discusses their implications. The final section concludes.

\section{Theorizing Uncertainty and Conflict Onset}

In this section, we construct a theoretical framework tying uncertainty to conflict and generate testable hypotheses. Despite the concept's prominence in the literature, links between uncertainty over conflict outcomes and conflict onset are often under-theorized or offer contrasting, at times contradictory, hypotheses (Bennett and Stam, 2004). Much of this confusion arises due to inconsistencies in the theoretical foundations of outcome uncertainty. We strive to clarify this ambiguous debate and formulate clear empirical expectations.

A compelling theory of outcome uncertainty's effect on conflict initiation must first specify what factors shape the magnitude of outcome uncertainty and then hypothesize how uncertainty ${ }^{2}$ influences state behavior. To do so, we develop a theory with three components. First, we address how polarity relates to the degree of uncertainty in any $n$-state setting. Second, we incorporate the broader distribution of capabilities into the conception of uncertainty because polarity alone masks variation in uncertainty levels. ${ }^{3}$ Third, we posit that the estimation complexity and likelihood of high war costs associated with greater outcome uncertainty induces caution. Explicitly stating an expectation of caution ties outcome uncertainty to state behavior. Putting the components together, we hypothesize that multipolar power distributions skewing toward perfect parity across statesthat is, parity amongst the major powers and parity amongst minor powers-have the greatest outcome uncertainty and that higher uncertainty reduces the likelihood of conflict onset.

\footnotetext{
${ }^{2}$ We refer to uncertainty over outcomes by the shorthand of uncertainty for the remainder of this work.

${ }^{3}$ Huth, Bennett and Gelpi (1992) and Huth, Gelpi and Bennett (1993) provide alternative, but complementary, conceptions of how these indicators affect uncertainty. However, our operationalization of the uncertainty measure in Section 3 is a stark departure from prior work.
} 
The first component of the theory posits that decreasing the number of great powers reduces uncertainty. Multipolar systems are the most uncertain as the conflict responses of many powerful actors can sway war's trajectory. Estimating whether the great powers abstain from conflict, or which side they join should they enter, muddy expectations of war's outcome. Concerns over abstention versus joining highlight why polarity is relevant even for conflicts that ultimately remain limited to minor powers. Moreover, the complexities associated with great power alliances which introduce the dual threats of buck-passing and entrapment elevate multipolarity's uncertainty (Waltz, 1979; Christensen and Snyder, 1990; Grant, Forthcoming). In contrast, simplicity and certainty are characteristic of bipolar and unipolar systems where few states can sway war outcomes. While the literature widely agrees that more poles increase uncertainty (Mearsheimer, 2001), the effect of uncertainty on war proclivity is contested. Typifying the logic that multipolarity fosters conflict, Waltz (1979, p. 168) argues that "rather than making states properly cautious and forwarding the chances of peace, uncertainty and miscalculations cause wars." A competing view claims that uncertainty pacifies by making states cautious when forced to divide their resources and attention between many potential threats (Deutsch and Singer, 1964; Singer, 1989). Others assert that unipolarity is prone to conflict due to either the challenges of rising states or the lack of balancing coalitions to deter military endeavors mounted by the hegemon (Monteiro, 2011; Layne, 2012).

Second, we argue that a balanced distribution of capabilities, as opposed to one of preponderance, creates greater uncertainty. The intuition is straightforward in a dyadic setting as conflict's outcome is less certain when the warring parties are evenly matched. This extends to multilateral settings where, under broad parity, any state's entry into war and alignment choice may meaningfully affect the outcome, whereas in hierarchical distributions, a single state's entry and alignment likely dictates conflict outcomes. While belligerents may be unsure of what the preponderant power will do, the estimation task lacks the complexity present in assessing how multiple evenly matched states will respond. 
Our assertion that balance increases uncertainty relates to a debate in the literature as to whether such balance fosters peace. Blainey (1988) argues that a balanced distribution incites conflict as opposing sides can both reach overly optimistic assessments of their prospects for victory. Alternatively, balance may promote peace because victory is unassured, or due to greater expected conflict costs (Waltz, 1959, 1979; Mearsheimer, 2001). Balance emerges from defensive actions to deter would-be aggressors and is thus definitionally associated with peace. Absent balance, conflicts occur "because there is nothing to prevent them" (Waltz, 1959, p. 232). A third contention is that the distribution of power has an indeterminate effect on conflict. Instead, conflict occurs when a disconnect exists between the balance of power and the balance of benefits - such as the distribution of wealth (Powell, 1999; Reed et al., 2008).

Consider how the interaction between the first and second components of our theory impacts the magnitude of outcome uncertainty. It follows that a multipolar system exhibiting parity both amongst the poles and amongst the weaker states will approach the upper bound of uncertainty. In contrast, uncertainty is minimized when there is unipolarity and when that unipolar system has a distinct hierarchy, even among the weaker states. That is, the second most powerful state enjoys preponderance over the third most powerful, and so forth. Between these outer bounds are an array of intermediate cases which reveal the insufficiency of using polarity or the capability distribution alone as a measure of uncertainty. For instance, it is unclear ex ante whether uncertainty is larger in a balanced bipolar system than in a hierarchical multipolar system. The measure introduced in the following section builds from these foundations and provides theoretical underpinnings for adjudicating between these more complicated intermediate cases.

Note that the discussion thus far spans multiple levels of analysis. For instance, structural realists typically argue that the greatest explanatory power derives from systemic attributes while bargaining theory looks to dyadic factors. Perhaps the potency of effects varies across levels. Indeed, a large literature suggests that such heterogeneity exists (Waltz, 1959; Singer, 1961; Gleditsch and 
Hegre, 1997; Ray, 2001; Chiozza and Goemans, 2011). This study examines how outcome uncertainty at multiple levels of analysis contributes to our understanding of conflict's origins. That is, the primary interest is shifting the level of our explanatory variable, not the unit at which the outcome is observed. A benefit of this approach, as highlighted in recent work (for example, Braumoeller 2008), is that systemic attributes can yield valuable insights when employed in conjunction with the typical dyadic measures.

The third component of the theory links uncertainty to state behavior, stipulating that states exercise caution when confronting higher outcome uncertainty. Within the extant literature, empirical expectations about outcome uncertainty's effect on conflict onset are ambiguous. How uncertainty tied to both polarity and the balance of power affects peace is debated. As a striking example of the ambiguity, structural realism generates contradictory expectations. Greater uncertainty under multipolarity promotes conflict, while greater uncertainty from a balanced distribution of power fosters peace. Ultimately, these debates hinge on unstated assumptions about actor responses to uncertainty (Bueno de Mesquita, 1981).

We argue actors respond to higher uncertainty with caution due to greater complexity in anticipating conflict outcomes and larger expected costs to conflict. Outcome uncertainty increases with the number of third parties that can join a conflict and meaningfully sway its course. Given that potential initiators are interested in assessing relevant third party reactions to conflict onset, the estimative complexity of this task increases with the degree of uncertainty. Gauging the decisions of numerous equally powerful states (high uncertainty) to join or abstain is more difficult than assessing the dominant state's reaction in a starkly hierarchical system (low uncertainty). Furthermore, the expected costs of fighting are greater in a high uncertainty environment. Conflict expansion resulting in greater destruction and fatalities becomes increasingly likely as more states are capable of altering the outcome. Empirical tests in the supporting appendix validate this assumption by 
demonstrating that conditional on a conflict occurring, greater uncertainty is associated with more states joining and higher fatalities.

With all three theoretical components in place, we now set forth two hypotheses. Given the anticipation of cautious behavior, it follows that conflict will occur less frequently during periods of high uncertainty in the international system.

H1: Higher systemic uncertainty, arising from an increase in the number of great powers and a more balanced distribution of capabilities, will reduce the total number of conflicts in the system and the likelihood of conflict onset within dyads.

As a further check, we test whether the hypothesized relationship holds at different levels of analysis. Our first hypothesis necessitates a system uncertainty measure that is identical across all observations within a given year. It is also plausible, however, that the decisions of potential belligerents might be influenced by only a subset of states, not all members of the international system. Accordingly, we construct regional uncertainty scores tailored to a specific geographic area or a specific dyad. Doing so enables a test of our propositions at a sub-systemic level while also highlighting the flexibility of the new measure. When constructing a dyad specific regional score, we identify a relevant set of actors unique to each dyad which, for example, could include neighbors of the two constituent states plus the major powers in that period. This construction excludes potentially irrelevant states from each observation's uncertainty score and introduces greater variation in the index.

H2: Higher regional uncertainty, arising from an increase in the number of great powers and a more balanced distribution of capabilities, will reduce the total number of conflicts in the region and the likelihood of conflict onset in that region's constitutive dyads. 
A final note is in order. As is clear from the theory's components, we assume that multiple actors' capabilities must be accounted for even when evaluating whether a single dyad will experience conflict. Bilateral uses of force do no transpire in a vacuum; conflict initiators consider the responses of third party actors. This might appear to be at odds with existing studies suggesting that conflict often remains contained to the two initiating parties (Gartner and Siverson, 1996; Smith, 1996; Werner, 2000). However, as these studies make clear, a conflict remaining dyadic does not imply the fighting parties neglect third party actors. Rather, states may be highly cognizant of the multilateral situation and only initiate conflict when they expect outside states that could swing conflict's outcome will remain on the sidelines. This account is consistent with our theory as it suggests that on the equilibrium path, most conflict remains dyadic because states err on the side of caution (do no fight) in more complex international environments. These complex scenarios where multiple states could enter and alter conflict's trajectory are the high uncertainty instances that we anticipate make conflict onset less likely. In sum, a measure accounting for third party actors is theoretically valid, and necessary, even if most conflicts remain bilateral. ${ }^{4}$

\section{A New Measure of Uncertainty}

In accordance with the hypotheses derived in the previous section, our focus is on measuring uncertainty about war outcomes. The standard approach in the literature to modeling war between two states (A and B from now on) is to treat war as a costly lottery. With this approach, the outcome of war is determined by a Bernouilli trial: state A wins with probability $p$ and loses to B with probability $1-p$. Parameter $p \in[0,1]$ is modeled with a simple contest success function that takes as argument the relevant factors affecting the two state's likelihoods of winning the war

\footnotetext{
${ }^{4}$ By this same reasoning, polarity is important even when analyzing conflicts that do not involve major powers.
} 
(Skaperdas, 1996). One of the most common functional forms used is the "ratio" form

$$
p=\frac{C_{A}}{C_{A}+C_{B}}
$$

where $C_{i}$ is a measure of state $i$ 's military capabilities and thus $p$ reflects a state's share of total dyadic capabilities. The dominant measure for $C_{i}$ in the international conflict literature, for instance, is the Composite Index of National Capability (CINC) score from the Correlates of War data set, developed by Singer, Bremer and Stuckey (1972). ${ }^{5}$

At the dyadic level, when war is modeled as a costly lottery, the uncertainty about the outcome of war depends on the value of $p$. In particular, the variance of this Bernoulli trial is $p(1-p)$, which is maximized at $\mathrm{p}=.5$, when the dyad is at parity. To characterize this uncertainty in a non-directed form, we redefine $p$ as $p=\frac{\min \left\{C_{A}, C_{B}\right\}}{C_{A}+C_{B}}$ to represent the balance of power within the dyad, which insures that the variance of the Bernoulli trial is increasing in $p$. Note that the random component of a Bernoulli trial allows for victories by the weaker state even when there is high, but incomplete, certainty about conflict outcomes, such as in the Vietnam War. To fix ideas, consider a more concrete parallel. A fair coin toss, analogous to cases where $\mathrm{p}=0.5$, has the maximum uncertainty about whether the coin lands heads or tails. In contrast, there is no uncertainty about the outcome when flipping a double-headed coin, which is equivalent to a conflict where $\mathrm{p}=0$.

Our goal is to develop a measure that goes beyond the dyadic level to characterize uncertainty of outcomes at the regional level, and ultimately, at the level of the international system. This measure should behave in accordance with our theoretical contentions that more poles and greater balance increase uncertainty. As discussed in the theory section, conflicts between two states rarely occur in isolation from third parties. Hence a good measure of outcome uncertainty should take into account interactions with, and between, other relevant states that might get involved in the

\footnotetext{
${ }^{5} \mathrm{CINC}$ score represents the average of a given state's proportion of total system capabilities in six areas: total population, urban population, iron/steel production, energy consumption, military personnel, and military expenditures.
} 
conflict between the two states. These relevant states can be major powers that show interest in disputes in different parts of the world, or they could be smaller states immediately neighboring the states involved in the dispute. An appropriate measure should allow flexibility regarding which states are considered relevant for a given dyad.

To develop a measure satisfying the above criteria, we generalize the idea of outcome uncertainty in a dyadic conflict to conflicts among a set of $\mathrm{N}$ countries. In this set, there exist a total of $\left(\begin{array}{c}N \\ 2\end{array}\right)=\frac{N(N-1)}{2}$ non-directed potential dyadic conflict interactions. The measure we describe provides a single statistic that summarizes the uncertainty about the outcomes of all these interactions.

For a given dyad $d$ between countries $\mathrm{A}$ and $\mathrm{B}$ in a given year, define the relevant set $R_{d}$ of $\mathrm{N} \in[2, \ldots, \bar{N}]$ countries that are relevant for a conflict between $\mathrm{A}$ and $\mathrm{B}$, where $\bar{N}$ represents the total number of countries in the system in that year. Relevance might be defined to include all states in the international system or it might be dyad specific_-defined based on factors like contiguity, major power status, trade relationships, or memberships in international organizations. Based on this set of countries with capabilities $C_{i}$ each, we define the following matrix of relative capabilities:

$$
P_{d}=\left[\begin{array}{cccc}
p_{11} & p_{12} & \ldots & p_{1 N} \\
p_{21} & \ldots & \ldots & \ldots \\
\ldots & \ldots & \ldots & \ldots \\
p_{N 1} & \ldots & \ldots & p_{N N}
\end{array}\right]
$$

where $p_{i j}=\frac{\min \left\{C_{i}, C_{j}\right\}}{\left(C_{i}+C_{j}\right)} \in[0, .5]$ in the $i$ th row and $j$ th column represents the non-directed balance of capabilities between states $i$ and $j .{ }^{6}$ Due to the way we defined $p$, the above matrix is symmetric, and a given cell can only include values between 0 and .5 . Denote $E_{1}$ as the first eigenvalue of

\footnotetext{
${ }^{6}$ The diagonal entries can be ignored, as the resulting metric will not depend on the specific value of $p_{i i}$ due to normalization. WLOG, we use $p_{i i}=0$ in our calculations.
} 
matrix $P_{d}{ }^{7}$ The first eigenvalue provides a single summary statistic of the overall uncertainty present in the included dyads which is ideal because it parsimoniously captures the underlying concept of interest. There are two limiting cases for $P_{d}$ that are theoretically interesting and will help capture the logic of our measure:

1. Perfect parity: When the relevant set is comprised of states that all have equal capabilities, all the non-diagonal cells of matrix $P_{d}$ will be equal to .5 . This limiting case is the largest value $E_{1}$ can take, call it $\bar{E}_{1}$. Theoretically, this represents the scenario with the highest level of outcome uncertainty.

2. Complete hierarchy: In this scenario, assume that there is a complete hierarchy between the states in the relevant set, in the sense that when states are ranked based on their capabilities, $p_{i j}=0$. That is, even the second most powerful state is totally insignificant when matched against the most powerful state, and the third most powerful is completely insignificant when matched against the second most powerful, and this type of relationship holds for the rest of the states. This limiting case gives the minimum value $E_{1}$ can take, call it $\underline{E}_{1}$. Theoretically, this represents the scenario with the lowest systemic uncertainty as all potential conflicts will have a clear predicted winner. Complete hierarchy is a theoretical extreme that is unlikely to exist in its pure form. However, some observed capability distributions will tend toward this extreme in which a state's military capacity is simultaneously dwarfed by a stronger state's capacity and dwarfs a weaker state's capacity. The degree to which observations approach this extreme, as opposed to cases where some or all adjacent relationships approach parity, is a revealing characteristic of that distribution that is of theoretical interest. ${ }^{8}$

\footnotetext{
${ }^{7}$ Since $P_{d}$ is symmetric, all of its eigenvalues, including $E_{1}$, are real. In this paper, we only use the largest eigenvalue in our measure. Smaller eigenvalues of $P_{d}$ could also provide valuable information about the link between uncertainty and the likelihood of conflict, which we leave as a topic for future research.

${ }^{8}$ Instances approaching complete hierarchy are observationally common, at least within subsets of states. Consider a hypothetical contested issue concerning The Bahamas in which the relevant states in ascending order of power are
} 
In any given year $y$, for a given dyad $d$, define the uncertainty score as

$$
\text { Uncertainty }_{y d}=\frac{E_{1}-\underline{E}_{1}}{\bar{E}_{1}-\underline{E}_{1}}
$$

It is clear from above that Uncertainty $_{y d} \in[0,1]$, and larger values represent more uncertainty. As shown in examples below, the amount of uncertainty in intermediate cases between the limiting extremes increases with the degree of widespread power parity.

\section{Weighted Uncertainty}

The above analysis treats each dyad equally when constructing a measure of uncertainty. Alternatively, one can weight cells of matrix $P_{d}$ such that dyads satisfying certain criteria receive a larger weight. For instance, it might be desirable that dyads involving more powerful states contribute to the overall score more. Define the weighting matrix $W_{d}$ as

$$
W_{d}=\left[\begin{array}{cccc}
w_{11} & w_{12} & \ldots & w_{1 N} \\
w_{21} & \ldots & \ldots & \ldots \\
\ldots & \ldots & \ldots & \ldots \\
w_{N 1} & \ldots & \ldots & w_{N N}
\end{array}\right]
$$

where $w_{i j}$ represents the weight assigned to dyad $i j$. An example specification that we will use in our empirical analysis is $w_{i j}=\frac{C_{A}+C_{B}-\underline{C}_{i j}}{\bar{C}_{i j}-\underline{C}_{i j}}$, where $\bar{C}_{i j}$ represents the dyad with the maximum total capability, and $\underline{C}_{i j}$ represents the weakest dyad. This weighting scheme makes sure that $w_{i j} \in[0,1]$, with the most powerful dyad getting $w_{i j}=1$, and the weakest dyad getting $w_{i j}=0$.

The Bahamas, Cuba, and the US. Based on 1992 CINC scores, the third most powerful states is insignificant when matched against the second most powerful state $(p<.02)$ and the second most powerful is insignificant when matched against the most powerful $(p<.02)$. 
If we define $P_{d}^{W}=W_{d} * P_{d}$ where each cell of $P_{d}$ is multiplied by its corresponding weight from $W_{d}$, the weighted uncertainty score for dyad $d$ in year $y$ is given as

$$
\text { Uncertainty } y_{y d}^{w}=\frac{E_{1}^{w}-\underline{E}_{1}^{w}}{\bar{E}_{1}^{w}-\underline{E}_{1}^{w}}
$$

with $E_{1}^{w}, \underline{E}_{1}^{w}$ and $\bar{E}_{1}^{w}$ defined similarly as in the unweighted case. ${ }^{9}$

This measure reflects the components of our theory and satisfies the criteria we mentioned in the beginning of this section. First, for any dyad, the measure takes into account the uncertainty in other relevant dyads. As the limiting cases illustrate, a balanced power distribution has high uncertainty. Second, weighting insures that stronger dyads, dyads that are more likely to get into conflict, or dyads that satisfy other user-specified criteria, contribute more to the overall uncertainty score. By emphasizing the most powerful dyads, the measure reflects our theoretical contention regarding polarity. Another feature of the measure is its flexibility to incorporate any standard or user-defined capability index or contest success function in defining $p_{i j} .{ }^{10}$ We discuss additional properties of the measure in the supporting appendix.

\section{System Uncertainty}

In accordance with the theories discussed in Section 2, of particular interest is uncertainty at the systemic level, where the relevant set of states for any dyad includes all states in the international system. System uncertainty scores are identical across all dyads in a given year because the annual relevant set is constant. In our sample for the empirical analysis, the size of the relevant set ranges from 23 in 1816 to 193 in 2007, with the unweighted system uncertainty score ranging from .20 in

\footnotetext{
${ }^{9}$ Besides weighting based on capabilities, we also consider weighting by alliance portfolio similarities (S-scores) and dyadic distance in our analyses (Signorino and Ritter, 1999).

${ }^{10}$ This flexibility is important because CINC scores have notable limitations-for example, CINC ranks China as the most powerful state since 1996. We leave the development of superior measures to future research.
} 
1946 to .37 in 1818 . The system uncertainty score could also be defined just for politically relevant dyads, or for dyads among major powers in the system. For our empirical analyses, we employ the system score for politically relevant dyads.

[Figure 1 about here.]

Figure 1 plots the system uncertainty score for politically relevant dyads from 1816 to 2007 . At first glance, the trends seem consistent with discussions of polarity which stipulate that multipolar systems involve more uncertainty while bipolar systems involve less. ${ }^{11}$ However, the trends also indicate that there are considerable variations within each systemic period, suggesting that other factors beyond polarity are needed to fully understand variations in systemic uncertainty. This is also apparent in Panel A of Table 1, where we plot the P matrix for the 5 most powerful states in the system in four different years. The top two tables represent years 1855 and 1912 from the multipolar period, while the bottom two represent years 1955 and 1990 from the bipolar world. As seen in the table, 1990 registers a larger uncertainty score than 1855 , which shows that beyond significant variations within each polarity period, years of bipolarity can entail more uncertainty than multipolar years when there is broader parity between both the poles and the non-poles.

[Table 1 about here.]

\section{Regional Uncertainty}

We also define a dyad-specific "regional" uncertainty score where the relevant set of states for a given dyad varies. In our empirical analyses, we define the relevant set in two ways: first, we divide

\footnotetext{
${ }^{11}$ Though older CINC scores are potentially more prone to measurement error, this is unlikely to account for the post-World War II decrease in uncertainty. Older uncertainty scores would be artificially increased only if measurement error took the non-random form of systematically coding states as closer to parity than they actually are. Additionally, if capabilities are measured with random error then the variance of error in our measure will be smaller than for a typical dyadic balance of capabilities measure.
} 
the world into five geographical regions, and all states in a dyad's geographical region are included in the relevant set for that dyad. Second, the relevant set is composed of all major powers and any state neighboring one of the states in the dyad, where neighboring is defined as land contiguous or separated by waters less than 400 nautical miles. As described above, these are only two ways of defining relevance among many others. Alternative definitions might exclude non-neighboring major powers from the relevant set or include all states in the international system if a dyad includes a major power.

\section{Extant Proxies for Uncertainty}

Perhaps due to the difficulties with operationalizing the concept of uncertainty, there have been few direct attempts in the international relations literature to measure outcome uncertainty. One measure occasionally used as an indicator for uncertainty is the concentration index (Ray and Singer, 1973), which reflects how concentrated power is within the international system:

$$
C O N=\sqrt{\frac{\sum C_{i}^{2}-1 / N}{1-1 / N}}
$$

where $C_{i}$ is country i's proportion of the total system capabilities. For any $\mathrm{N}>1$, it is easy to see that this measure attains its maximum value 1 when one state holds all the capabilities in the system, and its minimum 0 when power is equally divided across all states. Accordingly, scholars have used Dispersion $=1-C O N$ as a component in measures of uncertainty in the international system (Huth, Bennett and Gelpi, 1992; Huth, Gelpi and Bennett, 1993).

$C O N$ and our measure are closely related when states in the international system have roughly equal capabilities. In such scenarios, our system uncertainty measure takes a larger value, while $C O N$ gets smaller. When there are sizable imbalances in the international system, however, the two measures differ significantly. When there is a hegemon in the system that holds a large share of total capabilities, $C O N$ will approach its maximum value 1 . In such scenarios, $C O N$ mostly 
ignores relative capabilities between the remaining powers in the system. Our measure, however, captures variations of power imbalances and resulting variations in uncertainty among the weaker powers as well. Our measure attains its minimum value only when there is a complete hierarchy in the system, in which each state completely dominates the state that follows it in terms of capabilities. For $C O N$ to attain its maximum value, however, it is enough that the most powerful state dominates all other states, even when all the remaining N-1 states are at parity among each other.

Consider an example highlighting Uncertainty's superiority to Dispersion as a measure of outcome uncertainty. Panel B of Table 1 shows the distribution of capabilities from 1890 and 1992, noting the CINC scores of the six strongest states. We can summarize the two systems on the salient theoretical attributes of polarity and balance. The 1890 distribution is multipolar and relatively balanced while the 1992 distribution is not multipolar and is relatively unbalanced. As the theory section stipulated, outcome uncertainty increases with polarity and greater power parity. Accordingly, this is an easy test where 1890 should register higher uncertainty scores. However, only Uncertainty passes the test and identifies 1890 as the more uncertain year. Dispersion finds the inverse of the theoretical expectation, suggesting that while $C O N$ is a good measure of power concentration, it can obscure theoretically important variation in uncertainty levels. ${ }^{12}$

\section{Empirical Analysis}

In this section, we test our hypotheses by evaluating the effect of our new measure of uncertainty on conflict behavior using two specification forms. In the first specification, the unit of analysis is the non-directed politically relevant dyad year spanning a temporal range from 1816 to 2000 ,

\footnotetext{
${ }^{12}$ Uncertainty and Dispersion scores are based on all states in the specified years, not solely the six strongest states which are shown in Table 1 to highlight system attributes. The Uncertainty result holds in both its unweighted and weighted forms.
} 
which yields a dataset of 77,710 observations. The second specification instead uses system-year (185 observations) or region-year (677 observations) as the unit of analysis.

In our first specification, following prior research designs, we restrict the study to politically relevant dyads (Lemke and Reed, 2001). ${ }^{13}$ Non-directed dyads are appropriate as theories of uncertainty's role in conflict promotion speak to the likelihood of conflict, but are agnostic regarding which side initiates it. Moreover, the degree of outcome uncertainty for each state in a dyad is directly linked because an increase in one state's uncertainty implies a matching increase for the opposing state. As a result, using directed dyads would create an easy test by falsely inflating the sample size. Conflict Onset is a dichotomous outcome variable that includes only the initial year of a dispute between the two originating states as coded by the Militarized Interstate Disputes (MID) data set (Jones, Bremer and Singer, 1996; Ghosn, Palmer and Bremer, 2004). The variable equals one for conflict if the dispute entails the use of force-that is, for MIDs with a maximum hostility level of four or five, corresponding to "use of force" or "war" respectively. ${ }^{14}$

Our explanatory variables of interest consist of the uncertainty scores discussed in the prior section. The initial analysis employs System Uncertainty, both unweighted and weighted, which represents a single score generated for each year based on all politically relevant dyads. Weights on dyadic cells within the annual score matrix are based on (1) dyadic capabilities, (2) dyadic capabilities and geographic proximity, or (3) dyadic capabilities and alliance portfolio similarity. These procedures down-weight weak dyads, distant dyads, and dyads with similar foreign policy positions. To evaluate our second hypothesis, we use Regional Uncertainty which incorporates only major powers and neighbors of the constituent states for each dyadic observation. ${ }^{15}$ Thus

\footnotetext{
${ }^{13}$ Dyads must include contiguous states or at least one major power to be politically relevant.

${ }^{14}$ Findings are robust to alternative specifications of the outcome variable-such as including threats to use force or displays of force.

${ }^{15}$ Regional Uncertainty involves an additional qualification criteria. In non-contiguous major power-minor power dyads, we drop minor powers that neighbor the major power from the uncertainty score calculation. For instance,
} 
Regional Uncertainty scores, unweighted and weighted, vary across dyads within a given year. Weighting for Regional Uncertainty is analogous to the weighting for System Uncertainty. As a final means to examine uncertainty's effect across various levels of analysis, we include a measure Dyadic Uncertainty that ranges from 0 to 0.5 with higher values indicating greater uncertainty. The variable reflects a dyad's relative capabilities defined by the ratio form contest success function that we use to construct both System Uncertainty and Regional Uncertainty, but excludes any third party actors. As a baseline for comparison, we also consider the effect of Dispersion, calculated as 1-CON (Ray and Singer, 1973).

In the second specification form, which employs the system year or region year as the unit of analysis, the number of annual Conflict Onsets in a year is the outcome variable. System Uncertainty, defined as above, is the explanatory variable of interest for system level tests. For the region year specification, we split all states into five geographic clusters-Europe, Asia and Oceania, Middle East and North Africa, Sub-Saharan Africa, and the Americas-and calculate an annual uncertainty score for each region. This annual Regional Uncertainty score is the explanatory variable in region year tests.

\section{Control Variables}

We control for variables linked to conflict in prior studies. The voluminous democratic peace literature identifies an empirical association between joint dyadic democracy and lower rates of conflict (Oneal, Russett and Berbaum, 2003). Consequently, in our dyad year models, we include a binary indicator Joint Democracy that takes a value of one when both states in a dyad have Polity IV scores (Marshall and Jaggers, 2002) above six and zero otherwise. For the system and region

the 1990 US-Iraq dyad excludes the Dominican Republic which would otherwise qualify as contiguous with the US because the two states are separated by less than 400 miles of water. 
year models, Joint Democracy reflects the percentage of democratic dyads. ${ }^{16}$ State proximity and the presence of a shared border are strong predictors of conflict onset (Starr and Thomas, 2005; Vasquez, 2009). Contiguity is an ordinal control variable ranging from one for states that share a land or river border to six for states with no land border and separated by more than 400 miles of water. Alliance, ranging from one to four, measures whether members of a dyad share a formal defense pact, neutrality pact, or entente between them. We anticipate allied states are in conflict less frequently. All results are robust to coding Contiguity and Alliance as dichotomous variables.

Rivalry is a binary indicator of competing objectives between two states that consider the use of force a viable strategy. We opt for the Thompson (2001) rivalry dataset, which is qualitatively coded — there are no strict MID thresholds for qualification — with the primary criteria for inclusion being "the actors in question must regard each other as (a) competitors, (b) the source of actual or latent threats that pose some possibility of becoming militarized, and (c) enemies" (Thompson, 2001, 560). Following Carter and Signorino (2010), we account for temporal dependence in the binary outcome time-series cross-section data with polynomial terms-Peace Years, Peace Years ${ }^{2}$, and Peace Years ${ }^{3}$-measuring the duration of dyadic peace since the previous militarized dispute. We use EUGene version 3.204 (Bennett and Stam, 2000) to construct the full data set. Summary statistics are provided in the Online Appendix.

\section{Results \& Discussion}

The results presentation begins with an analysis of uncertainty's effect at the system level and then moves to the regional level. Each, in turn, starts with the system or region year count models before proceeding to the dyad year binary outcome specifications. With the system year as the unit of analysis, we use negative binomial regression due to the conflict count outcome variable. Results

\footnotetext{
${ }^{16}$ Annual count models also control for the number of dyads and major powers in the system or region (Correlates of War Project, Online, http://correlatesofwar.org 2008).
} 
in Model 1 of Table 2 corroborate our first hypothesis, as higher uncertainty at the system level induces a decline in the annual number of new conflicts when controlling for an array of variables, including the growth in total states over time. ${ }^{17}$ Using Clarify (King, Tomz and Wittenberg, 2000) to calculate the expected number of annual conflicts, we find that system uncertainty has a sizable substantive effect. The expected number of annual new conflicts is just under one when weighted system uncertainty is at its 90 th percentile value with all other covariates at their means. Shifting uncertainty to its 10 th percentile generates an additional 11 expected conflicts, plus or minus 4.5 at the $95 \%$ confidence level. An effect of this magnitude offers strong support for our contention that greater outcome uncertainty reduces conflict proclivity.

To further test system uncertainty's effect, we employ an alternative specification with the dyad year as the unit of analysis. Given the dichotomous outcome variable of conflict onset, we estimate the models using logistic regression with standard errors clustered at the dyad level. The results in Table 2 offer additional support for our first hypothesis that greater systemic uncertainty reduces the probability of conflict. Model 2 provides a baseline specification with the enumerated control variables, unweighted system uncertainty, and dyadic uncertainty. As anticipated, Rivalry and Contiguity are associated with more disputes, while Joint Democracy and Alliance ${ }^{18}$ have pacifying effects.

Of particular note are the effects of our uncertainty variables. As theorized, system uncertainty is negatively associated with conflict frequency, which suggests that the added complexity of a highly uncertain international environment fosters cautious state behavior. In contrast, there is a null finding for the effect of Dyadic Uncertainty, which indicates that outcome uncertainty that disregards third parties has no association with conflict. On the other hand, robustness tests which

\footnotetext{
${ }^{17}$ This statistically significant result is robust to employing alternative weightings that account for distance and alliance portfolio similarity in the System Uncertainty measure.

${ }^{18}$ Lower Contiguity values denote greater proximity and lower Alliance values denote tighter, or any, alignment.
} 
exclude Rivalry as a control variable find that Dyadic Uncertainty has a positive effect on conflict likelihood. This mirrors prior results (for example, Bennett and Stam 2004) which find that balanced dyadic capabilities increase conflict likelihood. Our null result in the baseline specification suggests the effect of balanced capabilities on conflict proclivity is most likely not due to outcome uncertainty, but instead is a result of rivalry being a common cause of dyadic balance of capabilities and conflict.

Models 3 through 5 include System Uncertainty in its various weighted forms as denoted by each model's superscript. ${ }^{19}$ In all instances, greater uncertainty has a highly significant effect reducing dispute onset. System Uncertainty's sizable effect reveals the importance of accounting for system level attributes when evaluating the causes of conflict. The findings suggest that only accounting for uncertainty at the dyadic level is a misspecification, as states clearly account for potential joiners when contemplating dispute initiation. Likelihood ratio tests confirm that adding the systemic uncertainty variable is a meaningful modeling improvement versus a reduced specification. ${ }^{20}$ In the Online Appendix we report a robustness check employing multilevel modeling with dyad-year observations nested at both the year and dyad levels, which provides substantively equivalent results. Taken together, these findings offer strong support for our contention that states exhibit cautious behavior when facing greater uncertainty.

[Table 2 about here.]

How does our uncertainty measure compare to the widely used Dispersion variable? A model (reported in the Online Appendix) that drops the uncertainty score while introducing Dispersion to the specification reveals a positive association between greater dispersion and more conflict.

\footnotetext{
${ }^{19}$ Weighting by (1) dyadic capabilities, (2) dyadic capabilities and geographic proximity, or (3) dyadic capabilities and alliance portfolio similarity are respectively denoted by superscripts of $(W),(W D)$, and $(W S)$.

${ }^{20} \mathrm{~A}$ likelihood ratio test comparing Model 3 to an otherwise identical model that excludes system uncertainty has a $p$-value below 0.001 .
} 
Given that past studies have used Dispersion, operationalized as 1-CON, as a proxy for uncertainty, this finding is contrary to our hypothesis. However, as discussed and illustrated in Section 3 , the proper interpretation of this result is ambiguous due to the tenuous theoretical linkages between uncertainty and capability concentration (Ray and Bentley, 2010). A Vuong test (Vuong, 1989) comparing non-nested regression specifications indicates that Model 3 using System Uncertainty provides a superior approximation of the "true" model as compared to one employing Dispersion. $^{21}$ Model 6 offers further evidence of the uncertainty score's relative merits versus those of the concentration index. When both included in the model, uncertainty's effect remains large and essentially unchanged while system concentration is no longer associated with conflict onset. Between its firm theoretical grounding and greater explanatory power, we find our measure to be a substantial improvement over the concentration index as a proxy for uncertainty.

Moving beyond statistical significance, we calculate the substantive effects of system uncertainty. To gauge the magnitude of uncertainty's effect on the likelihood of conflict, we generate predicted probabilities of conflict onset in two ways. First, what is uncertainty's effect within rivalrous dyads? These are particularly important cases, given their elevated baseline rates of conflict. We find that when decreasing system uncertainty from its 90th to its 10 th percentile, with all other variables held at their median values, the probability of conflict rises $5.9 \%$ points (plus or minus $2.5 \%$ points at the $95 \%$ confidence level) from $9.7 \%$ to $15.6 \%$.

Second, we turn to actual observations to identify uncertainty's effect. Our objective is to select observations balanced on all covariates except the level of system uncertainty. The US-UK 1868 and Argentina-UK 1982 dyads have similar values across all control variables. Both dyads are territorially separated, involved in a rivalry, share no alliance, include one major power, and have

\footnotetext{
${ }^{21}$ The Vuong test comparing Model 3 to one substituting Dispersion for system uncertainty has a $p$-value below 0.01. Note, Model 3 is also superior to a specification using polarity dummies rather than system uncertainty ( $p$-value $<0.001)$.
} 
similar magnitude power asymmetries. Only the prevailing level of system uncertainty differs, with high uncertainty in 1868 and low uncertainty in 1982. The supporting appendix contains a table summarizing the similarity of these two observations.

Consider how the different system uncertainty scores affect the probability of conflict. Figure 2 offers a graphical depiction of the following results. The 1868 UK-US dyad, in which the weighted system uncertainty score fell in the 89th percentile of its range, has a 3.0\% predicted probability of conflict, plus or minus $1.1 \%$ at the $95 \%$ confidence interval. In contrast, the 1982 UK-Argentina dyad, with a system uncertainty score in the 12 th percentile, has a $5.6 \%$ predicted probability of conflict, plus or minus $1.5 \%$. Increasing system uncertainty while holding all other values essentially constant, increases the likelihood of conflict by nearly $90 \%$, as shown in the right panel of Figure 2, with the scope of the $95 \%$ confidence interval denoted as well. In sum, greater system uncertainty has a clear pacifying effect on interstate relations.

[Figure 2 about here.]

To provide further substantive intuition for how our measure of uncertainty operates, consider the cases used in the previous analysis. We begin with a discussion of the peace that prevailed between the US and UK in 1868. A lack of conflict cannot be attributed to a lack of disputed matters. Dyadic tensions were elevated over both the Alabama Claims-American demands for compensation for British acts violating neutrality during the Civil War ${ }^{22}$ - and the perceived US threat to Canada. High system uncertainty provides a candidate explanation for why conflict did not erupt. Relative parity existed across a number of major powers at the time, as reflected by our measure's high score. Assessing a potential conflict's outcome demanded that each side consider the responses of a great many actors. Due to high system uncertainty, the multi-faceted diplomatic maneuverings in Europe and the Near East by peer states demanded British attention (Taylor,

\footnotetext{
${ }^{22}$ See Cook (1975) for a treatment of the Alabama Claims and Anglo-American relations during this period.
} 
1954). Great uncertainty and its attendant complexity plausibly induced caution and helped foster peace in the Anglo-American dyad.

In contrast, the dispute over the Falklands occurred in a comparatively certain environment. Any military conflict between the UK and Argentina would hinge upon their respective capabilities and the responses of the US and USSR. The low uncertainty level captured by our system measure reflects this structure of global power asymmetries. This is not to say uncertainty over the conflict's outcome was the sole, or even primary, cause of war. Extant literature highlights the conflict promoting roles of misperception (Lebow, 1985), bleak domestic prospects for the involved leaders (Bueno de Mesquita, 2006), and a British aversion to losing territory in accordance with prospect theory (Levy, 1992). Granting these factors, we suggest that the relative lack of parity in global military capabilities simplified the strategic picture. Critically, the participants needed to assess the American and Soviet responses. Gauging the former's reaction was of paramount importance to the junta, while the latter's role was likely to be limited given the UK's membership in NATO and Argentina's steadfast anticommunism (Lebow, 1985). While our measure does not reflect whether potential combatants make accurate assessments, it does capture the relative complexity of this task. As hypothesized, the more certain environment in 1982 was more conducive to conflict.

Does the observed relationship persist at different levels of analysis? Next, we consider whether uncertainty has a similar pacifying effect when measured at the regional, rather than systemic, level. An initial test employs the region year as the unit of analysis and a negative binomial model with the count of annual new conflicts in that region as the outcome variable. Recall that we split all states into five geographic clusters and calculate an annual uncertainty score in each region for this specification. ${ }^{23}$ As Model 7 of Table 3 indicates, greater uncertainty is associated with a decline in regional conflict onset, which accords with the second hypothesis. Regional uncertainty has a large substantive effect, as reducing its value from the 90th percentile to the 10th nearly

\footnotetext{
${ }^{23}$ Note that the count of new regional conflict onsets excludes inter-regional uses of force.
} 
quadruples the expected number of regional conflicts per year. Such a shift produces an extra 1.6 $( \pm 0.4)$ expected conflicts against a baseline of 0.6 when high regional uncertainty prevails. These results offer initial support for the contention that uncertainty's effect operates across levels of analysis.

We further explore the effects of regional uncertainty by turning to a dyad year specification with a binary conflict onset outcome variable. Unlike System Uncertainty, the Regional Uncertainty dyad year measure varies within a given year, as the constitutive matrix for the score contains different states for each dyad due to variation in bordering states. This formulation may offer a better reflection of the factors likely to influence policy-makers' decisions. For instance, when contemplating whether to use force in Somalia, Kenyan leaders may consider the responses from Ethiopia and the US but not from Ecuador. Models 8 through 10 of Table 3 provide logistic regression results incorporating regional uncertainty while controlling for the same variables as in prior logit specifications. We employ scores weighted by capabilities in all models while Models 9 and 10 additionally weight based on alliance portfolio similarity and distance respectively. As Table 3 shows, while the region year specification supports the second hypothesis, regional uncertainty in the dyad year models provides mixed results depending on the weighting. Unlike system uncertainty, a higher regional score does not uniformly reduce the probability of conflict. The hypothesized effect is only present when the measure weights dyads by capabilities and distance.

[Table 3 about here.]

To explore the mixed finding, we consider explanations for why state behavior may not exhibit the expected tendencies in some specifications. One immediate possibility is that the model is misspecified by only including a subset of third party states. That is, states may consider the whole system as their relevant set. A Vuong test corroborates this postulation, as Model 3 employing the system uncertainty measure provides a superior specification $-p$-value below $0.001 —$ compared to Model 8 using regional uncertainty. 
An alternative hypothesis to explain the mixed support is that, in some settings, potential conflict initiators are prone to miscalculating the level of uncertainty. Otherwise cautious actors may end up initiating conflict during periods of high uncertainty in situations where they fail to accurately assess the uncertainty level. This form of miscalculation ought to occur in circumstances where states are most prone to making mistakes regarding characteristics of their target state and the relevant set of third party actors.

When is information transparency likely to be greatest so as to minimize the chances of states miscalculating the level of uncertainty? The expected prudent behavior ought to be evident in these high-information cases if our proposition is accurate. We identify two scenarios that fit these conditions. First, geographic proximity may affect information levels. Closer dyads are less miscalculation prone than those separated by great distances. ${ }^{24}$ In accordance with this conjecture, regional uncertainty has a statistically significant pacifying effect in Model 10 which up-weights proximate dyads.

Second, the time period might influence the probability of miscalculation as recent years are marked by an increased velocity of information and global interactions (Keohane and Nye, 2000). Model 11 tests this proposition, examining regional uncertainty's effect for all observations after the Cold War, defined as post-1991. The results are consistent with our second hypothesis; higher regional uncertainty reduces the likelihood of conflict. Incidentally, note that the average number of states in the relevant set is greater after the Cold War. ${ }^{25}$ This fits the initial conjecture that the system is the proper relevant set specification as we observe greater state caution when the number of third parties incorporated into the regional variable increases. In sum, uncertainty's pacifying effect may be diluted by including a limited set of actors as opposed to the entire system, or in

\footnotetext{
${ }^{24}$ Note, this is not to say proximity reduces the amount of conflict; plainly it does not as contiguity is a strong predictor of conflict onset (Bennett and Stam, 2004; Vasquez, 2009). We merely suggest that disputes between bordering states are explained by mechanisms outside the scope of our analysis.

${ }^{25}$ Average size of the relevant set increases from 13.5 states before 1992 to 18.5 after the Cold War.
} 
settings prone to miscalculating the level of uncertainty. Once accounting for these possibilities, we find robust support for our second hypothesis.

Figure 3 illustrates regional uncertainty's substantive effect on conflict onset. For this analysis, we select representative observations from each model with similar baseline predicted probabilities of conflict. ${ }^{26}$ We calculate the relative change in conflict probability over this baseline rate when shifting Regional Uncertainty from its 90th percentile to its 10th percentile values. As noted, we cannot preclude the null hypothesis in the base specification with regional uncertainty weighted only by dyadic capabilities. However, in information-rich settings, decreasing uncertainty has the anticipated incendiary effect.

[Figure 3 about here.]

Our results illustrate the importance of testing theories at different levels of analysis. Systemic uncertainty's strong effect aligns with our theory positing that states are on average wary of estimation complexity and will pause when confronting greater outcome uncertainty. Regional uncertainty offers a more tenuous result. Though the peace-inducing effect of higher regional uncertainty is evident in region-year specifications as well as in information-rich dyadic settings, we do not observe the anticipated cautious behavior across all models. Finally, uncertainty at the dyadic level, which ignores the role of third parties, has no relationship with conflict. The positive correlation between outcome uncertainty's effect size and the level of analysis' geographic breadth offers an avenue for further inquiry linking uncertainty over conflict outcomes to conflict initiation. Furthermore, the heterogenous findings at the system, regional, and dyadic levels of analysis highlight the benefits of our measure's flexible construction, which allows researchers to define the relevant set of states for each observation in a theoretically informed manner.

${ }^{26}$ This analysis uses the following dyads: China-Taiwan 1976 for the all dyads model weighted by capabilities, Poland-Germany 1933 for the all dyads model weighted by capabilities and distance, and Russia-Latvia 1996 for post-Cold War dyads. All have similar baseline predicted probabilities of conflict of $6.0 \%, \pm 0.5 \%$. 


\section{Conclusion}

We have introduced a new theory specifying the determinants of outcome uncertainty and linking the degree of uncertainty to conflict behavior. When uncertainty over outcomes is elevated, which, for instance, occurs in multipolar settings with broad power parity between states, the probability of war onset is diminished. To test this contention, we developed a new measure of outcome uncertainty and highlighted its theoretical foundations, which make it a strong proxy for this central concept of interest. Once constructed, the variable allowed us to explore whether higher outcome uncertainty yields greater caution and fosters peace. Extensive empirical analysis confirms that it does. Elevated system uncertainty is strongly linked to reduced conflict probabilities. Our regional measure also corroborates, albeit tentatively, this relationship. We hope that this is only the beginning of investigation into uncertainty's effects as the new measure allows researchers to shift outcome uncertainty from the error term to a concrete right hand side variable. Furthermore, our theory's emphasis on third party actors highlights the fruitfulness of incorporating regional and systemic attributes to supplement the typical dyadic measures used to study conflict. Incorporating third parties into a theory of outcome uncertainty reveals the limitations, and questionable conclusions, of exclusively bilateral approaches.

We conclude with a substantive implication of our findings and a thought concerning the broader research agenda investigating uncertainty and its role in international conflict. The results of this article may have a striking implication for understanding or predicting future conflict. As evident in Figure 1, system uncertainty weighted by capabilities reached its lowest level in the final year of the available data. According to our results, this does not bode well for peace's prospects. In agreement with recent scholarship (for example, Monteiro 2011), the current configuration of power appears prone to unrest. Shifts toward parity, particularly amongst the most powerful nations, may actually be a harbinger of peace as states adopt more cautious postures due to increasing uncertainty over conflict outcomes. 
As for the wider role of uncertainty in conflict, our findings do not suggest all forms of uncertainty are pacifying, which would contradict the literature on asymmetric information over an opponent's capabilities or resolve (Fearon, 1995; Slantchev and Tarar, 2011). These forms of uncertainty, unmeasured in this study, may bolster or attenuate the observed effects. Instead, our focus is restricted to the uncertainty over outcomes arising from stochasticity inherent to conflict. Identifying proxies to reflect uncertainty over intentions or uncertainty over resolve and capabilities would be an ambitious and worthwhile next step. Novel theoretical work (for example, Fey and Ramsay 2011; Mitzen and Schweller 2011; Bas and Coe 2012) points to the importance and relevance of such efforts, as well as their difficulty. New measures and methods can generate theoretical insights regarding the - potentially conflicting - roles of different forms of uncertainty in conflict. 


\section{References}

Bas, Muhammet A. and Andrew J. Coe. 2012. “Arms Diffusion and War.” Journal of Conflict Resolution 56(4):651-674.

Bennett, D. Scott and Allan C. Stam. 2004. The Behavioral Origins of War. Ann Arbor, MI: University of Michigan Press.

Bennett, Scott and Allan Stam. 2000. "EUGene: A Conceptual Manual.” International Interactions 26(2):179-204.

Blainey, Geoffrey. 1988. The Causes of War. London, Macmillan.

Braumoeller, Bear. 2008. "Systemic Politics and the Origins of Great Power Conflict." American Political Science Review 102:77-93.

Bueno de Mesquita, Bruce. 1981. "Risk, Power Distributions, and the Likelihood of War.” International Studies Quarterly 25(4):541-568.

Bueno de Mesquita, Bruce. 1983. The War Trap. New Haven, CT: Yale University Press.

Bueno de Mesquita, Bruce. 2006. "Game Theory, Political Economy, and the Evolving Study of War and Peace." American Political Science Review 100(4):637-642.

Carter, David B. and Curtis S. Signorino. 2010. "Back to the Future: Modeling Time Dependence in Binary Data." Political Analysis 18:271-292.

Chiozza, Giacomo and H.E. Goemans. 2011. Leaders and International Conflict. Cambridge: Cambridge University Press.

Christensen, Thomas J. and Jack Snyder. 1990. "Chain Gangs and Passed Bucks: Predicting Alliance Patterns in Multipolarity.” International Organization 44(2):137-168. 
Cook, Adrian. 1975. The Alabama Claims: American Politics and Anglo-American Relations, 1865-1872. Ithaca, NY: Cornell University Press.

Correlates of War Project. Online, http://correlatesofwar.org 2008. State System Membership List, v2008.1.

Deutsch, Karl W. and J. David Singer. 1964. "Multipolar Power Systems and International Stability." World Politics 16(3):390-406.

Fearon, James D. 1995. “Rationalist Explanations for War.” International Organization 49(3):379_ 414.

Fey, Mark and Kristopher W. Ramsay. 2011. "Uncertainty and Incentives in Crisis Bargaining: Game-Free Analysis of International Conflict." American Journal of Political Science 55(1):146-169.

Gartner, Scott and Randolph M. Siverson. 1996. "War Expansion and War Outcome." Journal of Conflict Resolution 40(1):4-15.

Gartzke, Erik. 1999. "War is in the Error Term.” International Organization 53(3):567-587.

Ghosn, Faten, Glenn Palmer and Stuart Bremer. 2004. “The MID3 Data Set, 1993-2001: Procedures, Coding Rules, and Description.” Conflict Management and Peace Science 21(2):133-54.

Gleditsch, Nils Petter and Havard Hegre. 1997. "Peace and Democracy: Three Levels of Analysis." Journal of Conflict Resolution 41(2):283-310.

Grant, Keith A. Forthcoming. "Outsourcing Security: Alliance Portfolio Size, Capability, and Reliability." International Studies Quarterly .

Huth, Paul, Christopher Gelpi and D. Scott Bennett. 1993. "The Escalation of Great Power Militarized Disputes: Testing Rational Deterrence Theory and Structural Realism.” American Political Science Review 87(3):609-623. 
Huth, Paul K., D. Scott Bennett and Christopher Gelpi. 1992. "System Uncertainty, Risk Propensity, and International Conflict Among Great Powers." Journal of Conflict Resolution 36(3):478517.

Jervis, Robert. 1976. Perception and Misperception in International Politics. Princeton, N.J.: Princeton University Press.

Jervis, Robert. 1978. “Cooperation Under the Security Dilemma.” World Politics 30(2):167-214.

Jones, Daniel, Stuart Bremer and David Singer. 1996. “Miltarized Interstate Disputes, 1816-1992: Rationale, Coding Rules and Empirical Patterns." Conflict Management and Peace Science 15(2):163-213.

Keohane, Robert O. and Joseph S. Nye. 2000. “Globalization: What's New? What's Not? (And So What?)." Foreign Policy 118:104-119.

King, Gary, Michael Tomz and Jason Wittenberg. 2000. "Making the Most of Statistical Analyses: Improving Interpretation and Presentation.” American Journal of Political Science 44(2):34761.

Kugler, Jacek and Douglas Lemke. 1996. Parity and War: Evaluations and Extensions of the War Ledger. Ann Arbor, MI: University of Michigan Press.

Kydd, Andrew. 1997. “Game Theory and the Spiral Model.” World Politics 49(3):371-400.

Layne, Christopher. 2012. “This Time It's Real: The End of Unipolarity and the Pax Americana." International Studies Quarterly 56(1):203-213.

Lebow, Richard Ned. 1985. Miscalculation in the South Atlantic: The Origins of the Falklands War. In Psychology and Deterrence, ed. Robert Jervis, Richard Ned Lebow and Janice Gross Stein. Baltimore, MD: The Johns Hopkins University Press. 
Lemke, Douglas and William Reed. 2001. “The Relevance of Politically Relevant Dyads.” Journal of Conflict Resolution 45(1):126-44.

Levy, Jack S. 1992. "Prospect Theory and International Relations: Theoretical Applications and Analytical Problems." Political Psychology 12(3):283-310.

Maoz, Zeev. 1996. Domestic Sources of Global Change. Ann Arbor, MI: University of Michigan Press.

Marshall, Monty G. and Keith Jaggers. 2002. Polity IV Dataset [Computer file]. College Park, MD: University of Maryland.

Mearsheimer, John J. 2001. The Tragedy of Great Power Politics. New York: Norton.

Mitzen, Jennifer and Randall L. Schweller. 2011. "Knowing the Unknown Unknowns: Misplaced Certainty and the Onset of War." Security Studies 20:2-35.

Monteiro, Nuno P. 2011. "Unrest Assured: Why Unipolarity is Not Peaceful.” International Security 36(3):9-40.

Oneal, John R., Bruce Russett and Michael L. Berbaum. 2003. “Causes of Peace: Democracy, Interdependence, and International Organizations, 1885-1992.” International Studies Quarterly 47(3):371-393.

Powell, Robert. 1999. In the Shadow of Power: States and Strategies in International Politics. Princeton, N.J.: Princeton University Press.

Ray, James Lee. 2001. "Integrating Levels of Analysis in World Politics.” Journal of Theoretical Politics 13(4):355-388.

Ray, James Lee and J. David Singer. 1973. "Measuring the Concentration of Power in the International System.” Sociological Methods and Research 1(4):403-437. 
Ray, James Lee and Patrick Bentley. 2010. "Power Concentration and International Conflict: Is There a Connection?" Journal of Theoretical Politics 22(4):407-429.

Reed, William. 2003. "Information, Power, and War." American Political Science Review 97(4):633-41.

Reed, William, David H. Clark, Timothy Nordstrom and Wonjae Hwang. 2008. "War, Power, and Bargaining.” Journal of Politics 70(4):1203-1216.

Schelling, Thomas C. 1966. Arms and Influence. New Haven, CT: Yale University Press.

Signorino, Curtis S. and Jeffrey M. Ritter. 1999. "Tau-b or not Tau-b: Measuring the Similarity of Foreign Policy Positions.” International Studies Quarterly 43(1):115-144.

Singer, J. David. 1961. The Levels-of-Analysis Problem in International Relations. In The International System: Theoretical Essays, ed. Klaus Knorr and Sidney Verba. Princeton, N.J.: Princeton University Press.

Singer, J. David. 1989. System Structure, Decision Processes, and the Incidence of International War. In Handbook of War Studies, ed. Manus I. Midlarsky. Boston: Unwin Hyman.

Singer, J. David, Stuart Bremer and John Stuckey. 1972. Capability Distribution, Uncertainty, and Major Power War, 1820-1965. In Peace, War, and Numbers, ed. Bruce Russett. Sage: Beverly Hills.

Skaperdas, Stergios. 1996. “Contest Success Functions.” Economic Theory 7:283-290.

Slantchev, Branislav L. 2003. "The Principle of Convergence in Wartime Negotiations.” American Political Science Review 97(4):621-632.

Slantchev, Branislav L. and Ahmer Tarar. 2011. "Mutual Optimism as a Rationalis Explanation for War." American Journal of Political Science 55(1):135-148. 
Smith, Alastair. 1996. “To Intervene or Not to Interve: A Biased Decision.” Journal of Conflict Resolution 40(1):16-40.

Sobek, David and Joe Clare. 2013. "Me, Myself, and Allies: Understanding the External Sources of Power." Journal of Peace Research 50(4):469-478.

Starr, Harvey and G. Dale Thomas. 2005. "The Nature of Borders and International Conflict: Revisiting Hypotheses on Territory.” International Studies Quarterly 49(1):123-139.

Taylor, A.J.P. 1954. The Struggle for Mastery in Europe 1848-1918. UK: Oxofrd University Press.

Thompson, William R. 2001. "Identifying Rivals and Rivalries in World Politics.” International Studies Quarterly 45(4):557-86.

Trager, Robert F. 2010. "Diplomatic Calculus in Anarchy." American Political Science Review 104(2):347-368.

Vasquez, John A. 2009. The War Puzzle Revisited. Cambridge: Cambridge University Press.

von Clausewitz, Carl. 1976. On War. Princeton, N.J.: Princeton University Press.

Vuong, Quang. 1989. “Likelihood Ratio Tests for Model Selection and Non-Nested Hypotheses.” Econometrica 57:307-33.

Waltz, Kenneth N. 1959. Man, the State, and War: A Theoretical Analysis. New York: Columbia University Press.

Waltz, Kenneth N. 1979. Theory of International Politics. Long Grove, IL: Waveland Press.

Werner, Suzanne. 2000. "Deterring Intervention: The Stakes of War and Third-Party Involvement." American Journal of Political Science 44(4):720-732. 
Table 1: Properties of the Uncertainty Measure

Panel A: Varieties of Polarity—Non-Directed War Outcome Probabilities

Multipolar

\begin{tabular}{lccccc}
\hline \hline & UK & Russia & France & US & A-H \\
\hline UK & X & & & & \\
Russia & 0.36 & $\mathrm{X}$ & & & \\
France & 0.32 & 0.46 & $\mathrm{X}$ & & \\
US & 0.21 & 0.32 & 0.36 & $\mathrm{X}$ & \\
A-H & 0.18 & 0.28 & 0.31 & 0.45 & $\mathrm{X}$ \\
\hline \multicolumn{6}{c}{$1855:$ Uncertainty $=0.66$}
\end{tabular}

Bipolar

\begin{tabular}{lccccc}
\hline \hline & US & USSR & China & UK & India \\
\hline US & $\mathrm{X}$ & & & & \\
USSR & 0.40 & $\mathrm{X}$ & & & \\
China & 0.26 & 0.34 & $\mathrm{X}$ & & \\
UK & 0.16 & 0.22 & 0.36 & $\mathrm{X}$ & \\
India & 0.14 & 0.20 & 0.33 & 0.47 & $\mathrm{X}$ \\
\hline \multicolumn{5}{c}{$1955:$ Uncertainty $=0.58$}
\end{tabular}

Multipolar

\begin{tabular}{lccccc}
\hline \hline & US & Germany & Russia & UK & China \\
\hline US & $\mathrm{X}$ & & & & \\
Germany & 0.38 & $\mathrm{X}$ & & & \\
Russia & 0.36 & 0.47 & $\mathrm{X}$ & & \\
UK & 0.34 & 0.46 & 0.48 & $\mathrm{X}$ & \\
China & 0.34 & 0.45 & 0.48 & 0.49 & $\mathrm{X}$ \\
\hline \multicolumn{6}{c}{1912 : Uncertainty $=0.85$} \\
\end{tabular}

Bipolar

\begin{tabular}{lccccc}
\hline \hline & US & USSR & China & India & Japan \\
\hline US & $\mathrm{X}$ & & & & \\
USSR & 0.47 & $\mathrm{X}$ & & & \\
China & 0.43 & 0.46 & $\mathrm{X}$ & $\mathrm{X}$ & \\
India & 0.30 & 0.32 & 0.36 & $\mathrm{X}$ & \\
Japan & 0.29 & 0.31 & 0.34 & 0.49 & $\mathrm{X}$ \\
\hline \multicolumn{6}{c}{ 1990: Uncertainty $=0.75$} \\
\end{tabular}

Each entry indicates a dyad's power balance, calculated as $\frac{\min \left\{C_{A}, C_{B}\right\}}{C_{A}+C_{B}}$. By definition, the tables are symmetric. Blue text indicates cases distant from parity.

Panel B: CON vs. Uncertainty in Practice

\begin{tabular}{r|rrrrr|rrr|rc|}
\hline \hline & \multicolumn{4}{|c|}{ Top 6 State's CINC Scores } & \multicolumn{2}{c|}{ Attributes } & \multicolumn{2}{c}{ Measures } \\
& 1 & 2 & 3 & 4 & 5 & 6 & Multipolar & Balanced & Dispersion & Uncertainty \\
\hline 1890 & 0.18 & 0.17 & 0.16 & 0.13 & 0.10 & 0.10 & Yes & Yes & Low & High \\
1992 & 0.15 & 0.12 & 0.07 & 0.06 & 0.06 & 0.03 & No & No & High & Low \\
\hline \hline
\end{tabular}

Based on system attributes, 1890 should have greater outcome uncertainty than 1992. The Uncertainty measure, unweighted or weighted by capabilities, captures this while Dispersion, measured as 1-CON, does not. Scores are calculated using all states in the specified years. 
Table 2: System Uncertainty, Concentration, and Conflict

\begin{tabular}{|c|c|c|c|c|c|c|}
\hline & \multirow{2}{*}{$\begin{array}{c}\text { System Year } \\
(1) \\
\text { Unc }^{W}\end{array}$} & \multicolumn{5}{|c|}{ Dyad Year } \\
\hline & & $\begin{array}{l}(2) \\
\text { Unc }\end{array}$ & $\begin{array}{c}(3) \\
\mathrm{Unc}^{W}\end{array}$ & $\begin{array}{c}(4) \\
\mathrm{Unc}^{W S}\end{array}$ & $\begin{array}{c}(5) \\
\mathrm{Unc}^{W D}\end{array}$ & $\begin{array}{c}(6) \\
\mathrm{Unc}^{W}+\text { Disp }\end{array}$ \\
\hline System Uncertainty & $\begin{array}{l}-10.563^{* * *} \\
(1.570)\end{array}$ & $\begin{array}{l}-8.527^{* * *} \\
(1.197)\end{array}$ & $\begin{array}{l}-2.476^{* * *} \\
(0.511)\end{array}$ & $\begin{array}{l}-1.686^{* * *} \\
(0.486)\end{array}$ & $\begin{array}{l}-2.346^{* * *} \\
(0.517)\end{array}$ & $\begin{array}{c}-2.485^{* * *} \\
(0.531)\end{array}$ \\
\hline Dispersion & - & - & - & - & - & $\begin{array}{l}-0.036 \\
(0.891)\end{array}$ \\
\hline Dyadic Uncertainty & - & $\begin{array}{l}0.108 \\
(0.430)\end{array}$ & $\begin{array}{l}0.090 \\
(0.431)\end{array}$ & $\begin{array}{l}0.072 \\
(0.434)\end{array}$ & $\begin{array}{l}0.087 \\
(0.432)\end{array}$ & $\begin{array}{c}0.090 \\
(0.432)\end{array}$ \\
\hline Contiguity & - & $\begin{array}{l}-0.200^{* * *} \\
(0.030)\end{array}$ & $\begin{array}{l}-0.201^{* * *} \\
(0.030)\end{array}$ & $\begin{array}{l}-0.204^{* * *} \\
(0.030)\end{array}$ & $\begin{array}{l}-0.202^{* * *} \\
(0.030)\end{array}$ & $\begin{array}{c}-0.201^{* * *} \\
(0.030)\end{array}$ \\
\hline Joint Democracy & $\begin{array}{l}0.481 \\
(1.421)\end{array}$ & $\begin{array}{l}-0.675^{* * *} \\
(0.186)\end{array}$ & $\begin{array}{l}-0.664^{* * *} \\
(0.185)\end{array}$ & $\begin{array}{l}-0.659^{* * *} \\
(0.185)\end{array}$ & $\begin{array}{l}-0.650^{* * *} \\
(0.185)\end{array}$ & $\begin{array}{c}-0.664^{* * *} \\
(0.184)\end{array}$ \\
\hline Rivalry & - & $\begin{array}{l}1.340^{* * *} \\
(0.140)\end{array}$ & $\begin{array}{l}1.323^{* * *} \\
(0.140)\end{array}$ & $\begin{array}{l}1.301^{* * *} \\
(0.141)\end{array}$ & $\begin{array}{l}1.316^{* * *} \\
(0.140)\end{array}$ & $\begin{array}{l}1.323^{* * *} \\
(0.139)\end{array}$ \\
\hline Alliance & - & $\begin{array}{l}0.088^{*} \\
(0.044)\end{array}$ & $\begin{array}{l}0.080 \\
(0.044)\end{array}$ & $\begin{array}{l}0.072 \\
(0.044)\end{array}$ & $\begin{array}{l}0.080 \\
(0.044)\end{array}$ & $\begin{array}{c}0.080 \\
(0.044)\end{array}$ \\
\hline Number Major Powers & $\begin{array}{l}0.395^{* * *} \\
(0.096)\end{array}$ & - & - & - & - & - \\
\hline Number Dyads & $\begin{array}{l}0.000 \\
(0.000)\end{array}$ & - & - & - & - & - \\
\hline Constant & $\begin{array}{l}2.594^{* * *} \\
(0.382)\end{array}$ & $\begin{array}{l}-0.678^{*} \\
(0.322)\end{array}$ & $\begin{array}{l}-2.023^{* * *} \\
(0.231)\end{array}$ & $\begin{array}{l}-2.158^{* * *} \\
(0.229)\end{array}$ & $\begin{array}{l}-2.027^{* * *} \\
(0.233)\end{array}$ & $\begin{array}{c}-1.995^{* *} \\
(0.699)\end{array}$ \\
\hline lnalpha & $\begin{array}{l}-1.199^{* * *} \\
(0.250)\end{array}$ & & & & & \\
\hline$N$ & 185 & 77,710 & 77,710 & 77,710 & 77,710 & 77,710 \\
\hline
\end{tabular}

Notes: Superscripts on models indicate weighted by capabilities $(W)$, capabilities and S-scores $(W S)$, or capabilities and distance $(W D)$. Model 1 reports negative binomial regression results with the annual conflict count as the outcome. Models 2-6 report logistic regression results with standard errors clustered on the dyad. Temporal controls are not shown. 
Table 3: Regional Uncertainty and Conflict

\begin{tabular}{|c|c|c|c|c|c|}
\hline & Region Year & & & Dyad Year & \\
\hline & $\begin{array}{c}(7) \\
\text { Unc }^{W}\end{array}$ & $\begin{array}{c}(8) \\
\text { Unc }^{W}\end{array}$ & $\begin{array}{c}(9) \\
\text { Unc }^{W S}\end{array}$ & $\begin{array}{c}(10) \\
\mathrm{Unc}^{W D}\end{array}$ & $\begin{array}{c}(11) \\
\text { Post-Cold War }\end{array}$ \\
\hline Regional Uncertainty & $\begin{array}{l}-3.480^{* * *} \\
(0.495)\end{array}$ & $\begin{array}{l}-0.813 \\
(0.599)\end{array}$ & $\begin{array}{l}0.613 \\
(0.541)\end{array}$ & $\begin{array}{l}-1.062^{*} \\
(0.518)\end{array}$ & $\begin{array}{l}-3.354^{*} \\
(1.340)\end{array}$ \\
\hline Dyadic Uncertainty & - & $\begin{array}{l}0.101 \\
(0.440)\end{array}$ & $\begin{array}{l}-0.051 \\
(0.446)\end{array}$ & $\begin{array}{l}0.111 \\
(0.439)\end{array}$ & $\begin{array}{c}1.410 \\
(0.818)\end{array}$ \\
\hline Contiguity & - & $\begin{array}{l}-0.229^{* * *} \\
(0.031)\end{array}$ & $\begin{array}{l}-0.191^{* * *} \\
(0.032)\end{array}$ & $\begin{array}{l}-0.234^{* * *} \\
(0.031)\end{array}$ & $\begin{array}{c}-0.499^{* * *} \\
(0.087)\end{array}$ \\
\hline Joint Democracy & $\begin{array}{l}-0.896^{* *} \\
(0.331)\end{array}$ & $\begin{array}{l}-0.620^{* * *} \\
(0.184)\end{array}$ & $\begin{array}{l}-0.583^{* *} \\
(0.185)\end{array}$ & $\begin{array}{l}-0.628^{* * *} \\
(0.183)\end{array}$ & $\begin{array}{c}-0.822^{* *} \\
(0.306)\end{array}$ \\
\hline Rivalry & - & $\begin{array}{l}1.238^{* * *} \\
(0.149)\end{array}$ & $\begin{array}{l}1.226^{* * *} \\
(0.147)\end{array}$ & $\begin{array}{l}1.251^{* * *} \\
(0.149)\end{array}$ & $\begin{array}{l}1.061^{* * *} \\
(0.249)\end{array}$ \\
\hline Alliance & - & $\begin{array}{l}0.054 \\
(0.044)\end{array}$ & $\begin{array}{l}0.047 \\
(0.044)\end{array}$ & $\begin{array}{l}0.060 \\
(0.044)\end{array}$ & $\begin{array}{l}-0.060 \\
(0.080)\end{array}$ \\
\hline Number Great Powers & $\begin{array}{l}-0.165^{*} \\
(0.080)\end{array}$ & - & - & - & - \\
\hline Number Dyads & $\begin{array}{l}0.009^{* * *} \\
(0.003)\end{array}$ & - & - & - & - \\
\hline Constant & $\begin{array}{l}1.711^{* * *} \\
(0.281)\end{array}$ & $\begin{array}{l}-2.199^{* * *} \\
(0.304)\end{array}$ & $\begin{array}{l}-2.772^{* * *} \\
(0.318)\end{array}$ & $\begin{array}{l}-2.113^{* * *} \\
(0.271)\end{array}$ & $\begin{array}{l}-0.332 \\
(0.562)\end{array}$ \\
\hline lnalpha & $\begin{array}{l}-0.127 \\
(0.204)\end{array}$ & & & & \\
\hline$N$ & 677 & 77,710 & 77,553 & 77,710 & 12,336 \\
\hline
\end{tabular}

${ }^{*} p<0.05,{ }^{* *} p<0.01,{ }^{* * *} p<0.001$

Notes: Superscripts on models indicate weighted by capabilities $(W)$, capabilities and S-scores $(W S)$, or capabilities and distance $(W D)$. Model 7 reports negative binomial regression results with the annual regional conflict count as the outcome. Models 8-11 report logistic regression results with standard errors clustered on the dyad. Temporal controls are not shown. 


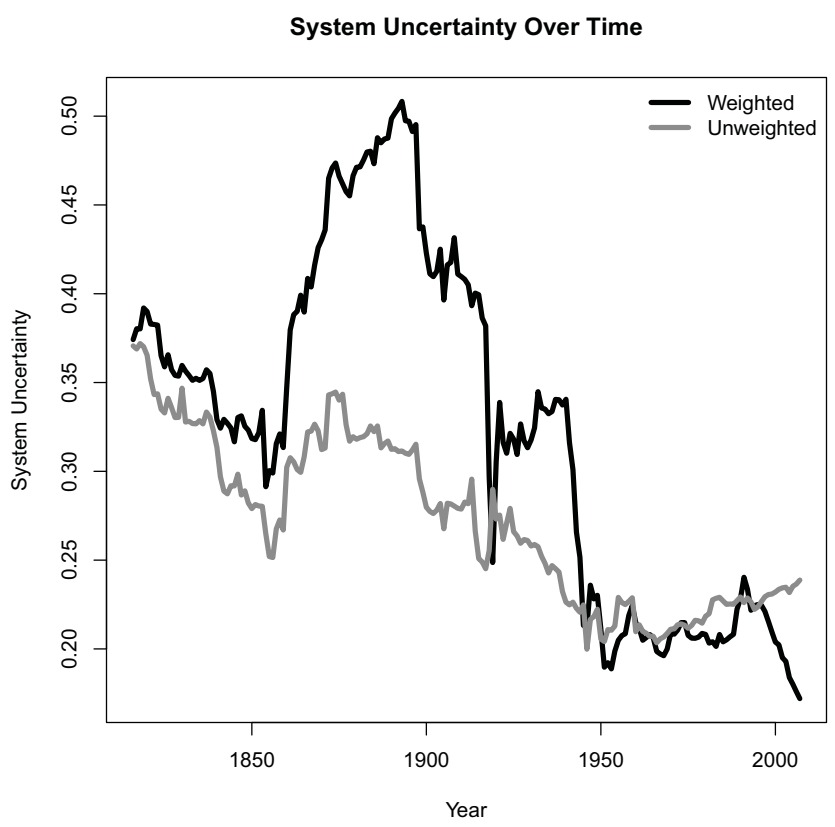

Figure 1: Weighted and Unweighted Scores (System Uncertainty) 


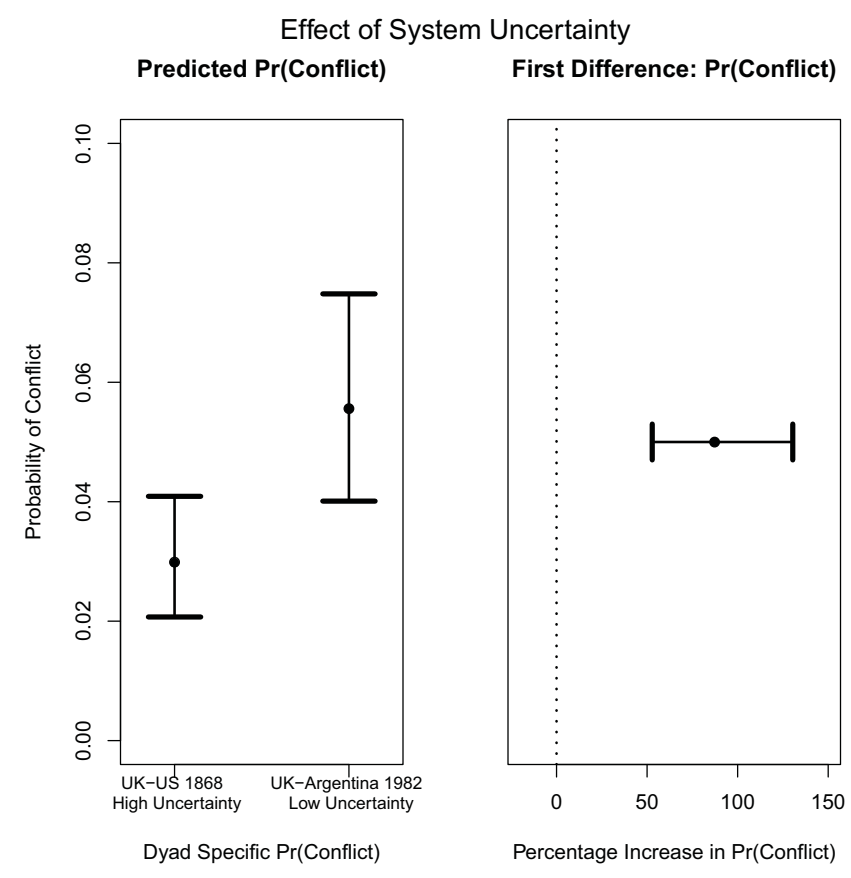

Figure 2: Effect of Decreasing System Uncertainty on Conflict Probability with 95\% Confidence Bounds 


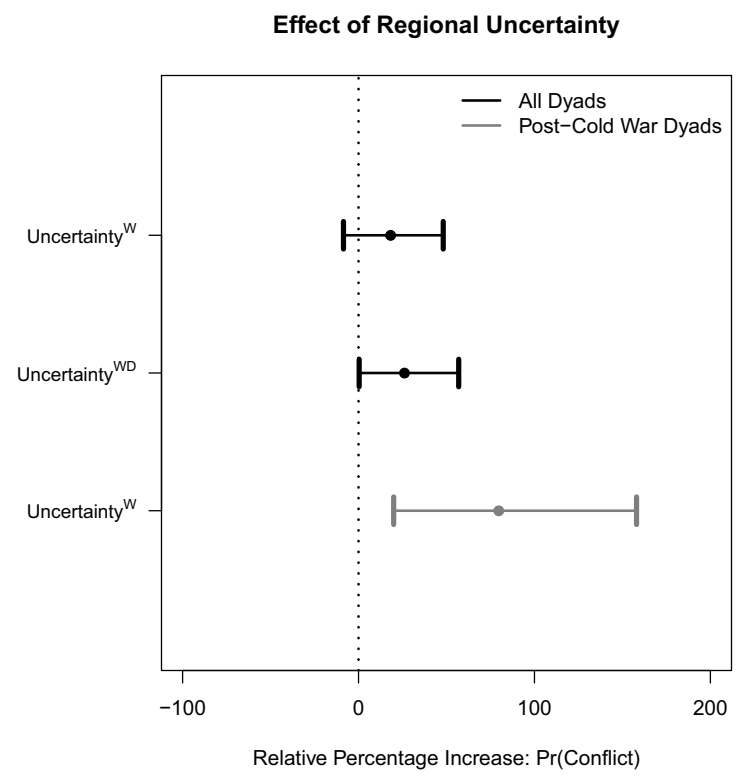

Figure 3: Effect of Decreasing Regional Uncertainty from 90th to 10th Percentile with 95\% Confidence Bounds. 